Ravindra L. Mehta

Josée Bouchard

Sharon B. Soroko

T. Alp Ikizler

Emil P. Paganini

Glenn M. Chertow

Jonathan Himmelfarb

Program to Improve

Care in Acute Renal Disease

(PICARD) Study Group

\section{Sepsis as a cause and consequence of acute kidney injury: Program to Improve Care in Acute Renal Disease}

Received: 16 February 2010

Accepted: 14 August 2010

Published online: 9 December 2010

(C) The Author(s) 2010. This article is published with open access at Springerlink.com

This article is discussed in the editorial available at: doi:10.1007/s00134-010-2097-9.

R. L. Mehta ( ) J. Bouchard .

S. B. Soroko

Division of Nephrology and Hypertension,

Department of Medicine,

University of California San Diego,

200 W Arbor Drive, San Diego,

CA 92103, USA

e-mail: rmehta@ucsd.edu

Tel.: +619-543-7310

Fax: +619-543-7420

T. A. Ikizler

Division of Nephrology,

Department of Medicine, Vanderbilt

University, Nashville, TN, USA

E. P. Paganini

Division of Nephrology,

Department of Medicine,

Cleveland Clinic Foundation,

Cleveland, OH, USA

\section{G. M. Chertow}

Division of Nephrology,

Department of Medicine,

Stanford University School of Medicine,

Palo Alto, CA, USA
J. Himmelfarb

Kidney Research Institute and Division of Nephrology, Department of Medicine, University of Washington, Seattle, WA, USA

Abstract Purpose: Sepsis commonly contributes to acute kidney injury (AKI); however, the frequency with which sepsis develops as a complication of AKI and the clinical consequences of this sepsis are unknown. This study examined the incidence of, and outcomes associated with, sepsis developing after AKI. Methods: We analyzed data from 618 critically ill patients enrolled in a multicenter observational study of AKI (PICARD). Patients were stratified according to their sepsis status and timing of incident sepsis relative to AKI diagnosis. Results: We determined the associations among sepsis, clinical characteristics, provision of dialysis, in-hospital mortality, and length of stay (LOS), comparing outcomes among patients according to their sepsis status. Among the 611 patients with data on sepsis status, $174(28 \%)$ had sepsis before AKI, 194 (32\%) remained sepsis-free, and 243 (40\%) developed sepsis a median of 5 days after AKI. Mortality rates for patients with sepsis developing after AKI were higher than in sepsis-free patients (44 vs. $21 \% ; p<0.0001)$ and similar to patients with sepsis preceding AKI (48 vs. $44 \% ; p=0.41$ ). Compared with sepsis-free patients, those with sepsis developing after AKI were also more likely to be dialyzed (70 vs. $50 \% ; p<0.001)$ and had longer LOS (37 vs. 27 days; $p<0.001)$. Oliguria, higher fluid accumulation and severity of illness scores, non-surgical procedures after $\mathrm{AKI}$, and provision of dialysis were predictors of sepsis after AKI.

Conclusions: Sepsis frequently develops after AKI and portends a poor prognosis, with high mortality rates and relatively long LOS. Future studies should evaluate techniques to monitor for and manage this complication to improve overall prognosis.

Keywords Acute kidney injury · Dialysis - Intensive care unit . Outcomes - Sepsis . Severity of illness

\section{Introduction}

In critically ill patients, acute kidney injury (AKI) is associated with a high mortality [1-5]; however, the mechanism(s) responsible for the increased mortality and morbidity risks associated with AKI remain elusive. AKI frequently complicates sepsis or septic shock $[1,6,7]$. So-called septic AKI has been independently associated with an increased risk for death and longer hospital stay [6]. Prior studies have focused on the incidence, risk 
factors, and prognosis of sepsis-induced AKI [6, 8-12]. Few studies have examined the incidence of, and consequences associated with, sepsis developing after AKI [13].

The Program to Improve Care in Acute Renal Disease (PICARD) was an observational study of 618 intensive care unit (ICU) patients with AKI from five academic medical centers in North America. PICARD was designed to identify demographic, clinical, and process of care factors associated with favorable and adverse outcomes after AKI [14]. We hypothesized that sepsis develops frequently after AKI, and is associated with mortality, nonrecovery of kidney function, and longer lengths of stay.

\section{Materials and methods}

Study participants

Over a 31-month period (February 1999 to August 2001), PICARD study personnel evaluated all critically ill patients consulted for AKI at five academic medical centers for potential study participation. Given the large number of ICU beds at Cleveland Clinic Foundation, we randomized one in six patients for possible study inclusion, to avoid single-center over-representation. A detailed description of PICARD inclusion and exclusion criteria, data elements, data collection, and management strategies has been described elsewhere [14]. In PICARD, AKI was defined as an increase in serum creatinine $\geq 44 \mu \mathrm{mol} / \mathrm{L}$ when baseline serum creatinine was $<133 \mu \mathrm{mol} / \mathrm{L}$, or an increase in serum creatinine $\geq 88 \mu \mathrm{mol} / \mathrm{L}$ when baseline serum creatinine was $\geq 133 \mu \mathrm{mol} / \mathrm{L}$ and $<442 \mu \mathrm{mol} / \mathrm{L}$ (to convert $\mu \mathrm{mol} / \mathrm{L}$ into $\mathrm{mg} / \mathrm{dL}$, divide by 88.4 ). Baseline serum creatinine was defined as the closest value within 6 months of hospital admission. Exclusion criteria included age $<18$ years, prisoners, pregnancy, serum creatinine $>442 \mu \mathrm{mol} / \mathrm{L}$, previous dialysis, kidney transplantation, AKI from urinary tract obstruction, and hypovolemia responsive to fluid. All interventions were determined by the attending physicians and not influenced by the study personnel. The institutional review boards at each site approved the study protocol. Informed consent was required from all study participants or their proxy. In this study, we included all patients $(611 / 618 ; 99 \%)$ who had data available on sepsis status.

\section{Determination of sepsis status}

Patients were evaluated for the presence of systemic inflammatory response syndrome (SIRS) and sepsis as defined by American College of Chest Physicians/Society of Critical Care Medicine guidelines [15]. Specifically, SIRS was defined as a systemic inflammatory response to an unspecified stimulus manifested by the presence of two or more of the following: (a) body temperature greater than $38^{\circ} \mathrm{C}$ or less than $36^{\circ} \mathrm{C}$; (b) heart rate greater than 90 beats/ min; (c) on a ventilator, or tachypnea, manifested by a respiratory rate greater than 20 breaths/min, or hyperventilation, as indicated by a $\mathrm{PaCO}_{2}$ of less than $32 \mathrm{mmHg}$; and (d) a white blood cell count greater than $12,000 / \mathrm{mm}^{3}$ or less than $4,000 / \mathrm{mm}^{3}$, or the presence of more than $10 \%$ immature neutrophils. Sepsis was diagnosed when patients met criteria for SIRS and an infectious source was documented or strongly suspected on the basis of clinical suspicion and tests ordered by treating physicians [15]. The sepsis status was computed daily from these variables. Patients were then classified into one of three groups: patients who remained sepsis-free, those who developed sepsis prior to AKI diagnosis, and those who developed sepsis post-AKI diagnosis. Data on focus of infection during ICU stay were derived from ICD-9 codes (Table 1).

\section{Definitions}

We computed fluid balance for each day using the sum of daily fluid intake (in liters) from which we subtracted total output (in liters). To quantify cumulative fluid balance in relation to body weight, we used the following formula: ( daily (fluid intake (L) - total output (L))/ body weight (in kg))/100 [16]. "Fluid overload" was defined as $>10 \%$ fluid accumulation over baseline weight at hospital admission [17]. Invasive non-surgical procedures were tracked through the observation period. These included pulmonary artery catheter placement, cardiac procedures (other intracardiac catheters, angioplasties, atherectomies, pacemaker placements), extracorporeal membrane oxygenation (ECMO), chest tube placement, bronchoscopy, thoracentesis, paracentesis, burn-related procedures, radiologic procedures (stents, other angioplasties), internal organ biopsy, plasmapheresis, and transjugular intrahepatic portosystemic shunt (TIPS). Recovery of kidney function was defined as a final serum creatinine concentration either within $20 \%$ or $44 \mu \mathrm{mol} / \mathrm{L}$ of the baseline serum creatinine value. For patients requiring dialysis, the definition of recovery also included independence from dialysis for at least 3 days prior to death or hospital discharge. Sequential Organ Failure Assessment (SOFA) scores [18] were computed daily.

\section{Statistical analyses}

Continuous variables were expressed as mean \pm standard deviation (SD) or median and interquartile range and compared by using general linear models with Tukey's adjustment for multiple pairwise comparisons or the Wilcoxon rank-sum test, where appropriate. Categorical variables were expressed as proportions and compared with the chi-square or Fisher exact test, where 
Table 1 Selected patient characteristics

\begin{tabular}{|c|c|c|c|c|}
\hline & $\begin{array}{l}\text { Sepsis pre-AKI } \\
\text { diagnosis } \\
(n=174)\end{array}$ & $\begin{array}{l}\text { Sepsis-free } \\
(n=194)\end{array}$ & $\begin{array}{l}\text { Sepsis post-AKI } \\
\text { diagnosis } \\
(n=243)\end{array}$ & $p$ value \\
\hline Mean age (years) & $55.2 \pm 16.2$ & $62.9 \pm 15.3$ & $59.8 \pm 16.3$ & $\begin{array}{l}<0.0001^{\mathrm{a}} \\
0.004^{\mathrm{c}}\end{array}$ \\
\hline$\%$ Male & $60 \%$ & $59 \%$ & $59 \%$ & NS \\
\hline$\%$ White & $78 \%$ & $82 \%$ & $79 \%$ & NS \\
\hline \% Chronic kidney disease & $25 \%$ & $42 \%$ & $23 \%$ & $0.0003^{\mathrm{a}}<0.0001^{\mathrm{b}}$ \\
\hline \% With surgery prior to AKI diagnosis & $44 \%$ & $54 \%$ & $52 \%$ & $0.03^{\mathrm{a}}$ \\
\hline RIFLE category & & & & 0.35 \\
\hline Not classified $(n=120)^{\mathrm{d}}$ & $29(24 \%)$ & $45(38 \%)$ & $46(38 \%)$ & \\
\hline Risk $(n=99)$ & $30(30 \%)$ & $36(36 \%)$ & $33(33 \%)$ & \\
\hline Injury $(n=49)$ & $15(31 \%)$ & $12(24 \%)$ & $22(45 \%)$ & \\
\hline Failure $(n=302)$ & $95(31 \%)$ & $86(28 \%)$ & $121(40 \%)$ & \\
\hline \multicolumn{5}{|l|}{ Etiology of AKI (not mutually exclusive) } \\
\hline Acute tubular necrosis/ischemia & $80 \%$ & $63 \%$ & $69 \%$ & 0.0005 \\
\hline Cardiac & $13 \%$ & $23 \%$ & $21 \%$ & 0.02 \\
\hline Liver factors & $7 \%$ & $10 \%$ & $14 \%$ & NS \\
\hline Nephrotoxic & $26 \%$ & $26 \%$ & $27 \%$ & NS \\
\hline Obstruction & $2 \%$ & $1 \%$ & $1 \%$ & NS \\
\hline Pre-renal & $15 \%$ & $17 \%$ & $17 \%$ & NS \\
\hline Multifactorial & $8 \%$ & $5 \%$ & $7 \%$ & NS \\
\hline \multicolumn{5}{|l|}{ Etiology of sepsis (not mutually exclusive) } \\
\hline Positive hemocultures & $76 / 141$ & $9 / 67$ & $88 / 180$ & $<0.0001^{\mathrm{a}, \mathrm{b}}$ \\
\hline Gram positive & $47 / 141$ & $7 / 67$ & $61 / 180$ & $<0.0001^{\mathrm{a}, \mathrm{b}}$ \\
\hline Gram negative & $22 / 141$ & $1 / 67$ & $23 / 180$ & $<0.0001^{\mathrm{a}, \mathrm{b}}$ \\
\hline Unknown & $7 / 141$ & $1 / 67$ & $4 / 180$ & $<0.0001^{\mathrm{a}, \mathrm{b}}$ \\
\hline Positive cultures, other & $51 / 174$ & $34 / 194$ & $84 / 243$ & $0.0003^{\mathrm{a}, \mathrm{b}}$ \\
\hline \multicolumn{5}{|l|}{ Type of infection } \\
\hline Septicemia ${ }^{\mathrm{a}}$ & 44 & & 33 & \\
\hline Bacteremia & 1 & & 1 & \\
\hline \multicolumn{5}{|l|}{ Bacterial infection not otherwise } \\
\hline Specified & 0 & & 1 & \\
\hline Endocarditis & 6 & & 3 & \\
\hline Pneumonia & 17 & & 9 & \\
\hline Influenza & 2 & & 0 & \\
\hline Pleurisy/empyema & 2 & & 3 & \\
\hline Anal abscess & 1 & & 0 & \\
\hline Peritonitis & 3 & & 2 & \\
\hline Liver abscess & 1 & & 0 & \\
\hline Cholangitis & 0 & & 1 & \\
\hline Pancreatitis & 9 & & 8 & \\
\hline Urinary tract infection & 4 & & 1 & \\
\hline$\%$ Oliguric at AKI diagnosis & $23 \%$ & $23 \%$ & $34 \%$ & $0.022^{\mathrm{b}}$ \\
\hline Mean number of oliguric days post-AKI diagnosis & $7.0 \pm 10.4$ days & $3.1 \pm 5.8$ days & $7.8 \pm 10.5$ days & $\begin{array}{l}0.011^{\mathrm{c}} \\
<0.0001^{\mathrm{a}} \\
<0.0001^{\mathrm{b}}\end{array}$ \\
\hline Cumulative fluid balance at AKI diagnosis (L) & $6.6 \pm 7.7$ & $3.0 \pm 5.3$ & $3.7 \pm 6.4$ & $\begin{array}{l}<0.0001^{\mathrm{a}} \\
0.067^{\mathrm{b}} \\
0.0002^{\mathrm{c}}\end{array}$ \\
\hline $\begin{array}{l}\text { Mean } \% \text { fluid accumulation adjusted for } \\
\text { body weight at AKI diagnosis }\end{array}$ & $8.2 \pm 9.5$ & $4.0 \pm 7.6$ & $4.5 \pm 7.6$ & $\begin{array}{l}<0.0001^{\mathrm{a}} \\
<0.0001^{\mathrm{c}}\end{array}$ \\
\hline Mean glucose at AKI diagnosis $(\mathrm{mmol} / \mathrm{L})$ & $8.8 \pm 4.3$ & $8.4 \pm 3.4$ & $8.4 \pm 2.2$ & NS \\
\hline Mean SOFA score at AKI diagnosis & $8.5 \pm 3.8$ & $5.9 \pm 2.9$ & $7.1 \pm 3.8$ & $\begin{array}{l}<0.0001^{\mathrm{a}} \\
0.0003^{\mathrm{b}}\end{array}$ \\
\hline Mechanical ventilation & $61 \%$ & $24 \%$ & $35 \%$ & $\begin{array}{l}<0.0001^{\mathrm{a}} \\
0.026^{\mathrm{b}} \\
<0.0001^{\mathrm{c}}\end{array}$ \\
\hline Pressor support & $43 \%$ & $28 \%$ & $26 \%$ & $\begin{array}{l}0.002^{\mathrm{a}} \\
0.77^{\mathrm{b}} \\
0.0003^{\mathrm{c}}\end{array}$ \\
\hline
\end{tabular}

AKI acute kidney injury, SOFA Sequential Organ Failure Assessment, NS not ${ }^{\mathrm{d}}$ Not classified include patients who did not meet the $50 \%$ increase in serum significant

a Sepsis pre-AKI versus sepsis-free creatinine

b Sepsis-free versus sepsis post-AKI

e Defined as ICD-9 codes 038.0-038.9

${ }^{\mathrm{c}}$ Septic pre- versus post-AKI 
appropriate. We examined the in-hospital time to death using the Kaplan-Meier product limit estimate and compared survival curves using the log-rank test.

We determined independent predictors of sepsis developing after AKI using logistic regression. We constructed the model with backward selection considering these variables: age, gender, chronic obstructive pulmonary disease, chronic kidney disease (CKD), diabetes, human immunodeficiency virus (HIV), hypertension, previous chemotherapy, radiation therapy, steroid therapy, leukemia, lymphoma, oliguria status at AKI diagnosis (urine output $\leq 400 \mathrm{~mL} /$ day), oliguria $\geq 3$ days, number of oliguric days, hyperglycemia, blood urea nitrogen (BUN) and serum osmolality, mechanical ventilation at AKI diagnosis, SOFA score, surgery and nonsurgical procedures prior to AKI, antibiotic use prior to AKI and dialysis requirement, and fluid overload status. Effect modification was evaluated by including multiplicative interaction terms for selected variables. We included in the multivariable model variables with Wald chi-square $p$ value $\geq 0.10$ on bivariate screening. Factors not included in multivariable models were re-entered individually to evaluate for residual confounding. In logistic regression models, discrimination was assessed by using the area under the receiver operating characteristic (ROC) curve. Calibration was assessed by using the Hosmer-Lemeshow goodness-of-fit test. All statistical tests were two-sided and $p<0.05$ was considered significant. Statistical analyses were conducted by using SAS 9.2 (SAS Institute, Cary, NC, USA).

\section{Results}

Among the 611 patients with available data on sepsis status throughout hospitalization (99\% of the 618-patient cohort), 174 (28\%) were septic prior to AKI diagnosis (septic AKI), 194 (32\%) patients remained sepsis-free, and $243(40 \%)$ developed sepsis 5 days (IQ range 2-9 days) after AKI diagnosis (Fig. 1). After AKI diagnosis was made, the incidence of sepsis post-AKI and the time to develop sepsis post-AKI were similar in patients who did and did not require dialysis. As opposed to patients who remained sepsis-free, those who developed sepsis post-AKI were more often oliguric at AKI diagnosis, had higher severity of illness scores, and were less likely to have pre-existing CKD (Table 1). Compared with patients with sepsis pre-AKI, those with sepsis postAKI were older, more often oliguric at AKI diagnosis, and had lower cumulative fluid balance (Table 1). There were no differences in the frequency and type of organisms between patients who developed sepsis pre- or postAKI. Forty-five percent of patients with sepsis pre-AKI and $23.5 \%$ of patients with sepsis post-AKI had one or more infection ICD-9 code.

Among patients with AKI requiring dialysis $(n=391), 170(43.5 \%)$ developed sepsis after AKI. Eighty-seven of these 170 dialyzed patients $(51 \%)$ had sepsis prior to dialysis initiation, whereas 83 (49\%) developed sepsis on average 4 days (IQ range 2-7 days) post-dialysis initiation. In these 83 patients, the incidence of sepsis post-continuous renal replacement therapy (CRRT) and intermittent hemodialysis (IHD) was similar (52 vs. $48 \%$ ).

Predictors for the development of sepsis

Independent predictors of the development of incident sepsis post-AKI included oliguria $\geq 3$ days, higher percentages of days with fluid overload post-AKI diagnosis, invasive non-surgical procedures post-AKI diagnosis, high severity of illness scores, and dialysis requirement (either intermittent or continuous renal replacement therapy) (Table 2).
Fig. 1 Incidence and timing of sepsis in all patients

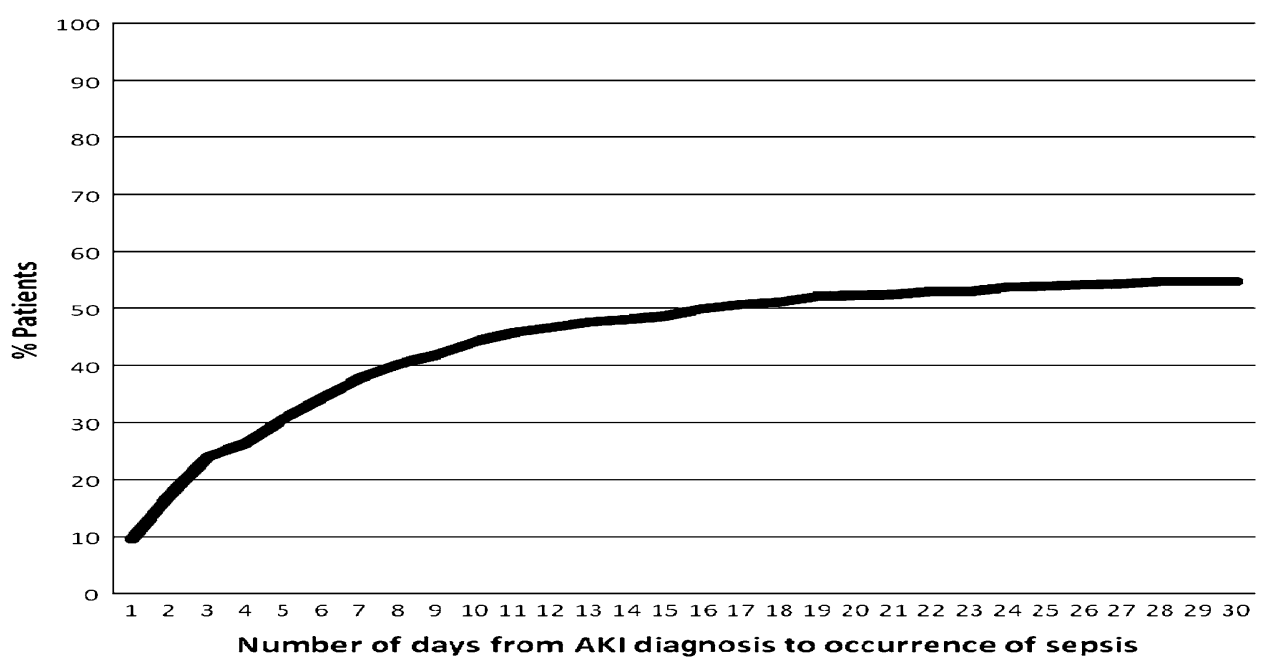


Table 2 Significant predictors of incident sepsis after the diagnosis of acute kidney injury

Logistic regression

Incidence of sepsis post-AKI diagnosis ${ }^{\mathrm{a}}$

Parameter

\begin{tabular}{ccc} 
Coefficient & OR & $95 \% \mathrm{CI}$ \\
\hline-1.1319 & & \\
-0.9142 & 0.40 & $0.26-0.63$ \\
0.6554 & 1.93 & $0.99-3.74$ \\
1.2236 & 3.40 & $1.49-7.76$ \\
0.1086 & 1.12 & $1.04-1.20$ \\
0.5078 & 1.66 & $1.05-2.64$ \\
0.4552 & 1.58 & $1.01-2.45$ \\
0.5571 & 1.75 & $1.15-2.66$
\end{tabular}

Intercept

Chronic kidney disease

Steroid therapy

At least 3 days of oliguria ${ }^{\mathrm{b}}$

SOFA score at AKI diagnosis (per 1 point of score)

$>25 \%$ of post-AKI days with cumulative fluid balance $>10 \%$ of body weight

Provision of dialysis

Invasive non-surgical procedure post-AKI

${ }^{b}$ Days of oliguria prior to sepsis in septic patients, prior to end of

$A K I$ acute kidney injury, SOFA Sequential Organ Failure Assessment

${ }^{\mathrm{a}}$ Area under ROC curve $=0.74$, Hosmer-Lemeshow $x^{2}=0.57$ nephrology consult in non-septic patients

Timing of sepsis and outcomes

The in-hospital mortality rate was significantly higher in patients who developed sepsis post-AKI than in patients without sepsis through their hospital course (44 vs. 21\%; $p<0.001)$ and similar to that of patients with sepsis preAKI (44 vs. $48 \% ; p=0.41$; Figs. 2,3 ). In dialyzed and non-dialyzed patients, sepsis was associated with $20 \%$ higher absolute mortality rates, irrespective of whether sepsis occurred before or after AKI (Fig. 4). In patients with sepsis post-AKI, the mortality rate was similar regardless of the timing of sepsis post-AKI (38\% for sepsis within 3 days, $51 \%$ after 4 to 10 days, and $42 \%$ after 10 days following AKI diagnosis; $p=0.18$ ). Additionally, in-hospital mortality rates were similar regarding the timing of sepsis in relation to dialysis initiation (54 vs. $46 \%$ before or after dialysis initiation; $p=0.28$ ). Compared with patients who remained sepsisfree, those with sepsis post-AKI were also more likely to be dialyzed (70 vs. 50\%; $p<0.001)$ and had longer median lengths of stay ( 37 vs. 27 days; $p<0.001$ ). When evaluating mortality, lengths of stay and rates of recovery of kidney function, results were similarly poor whether sepsis developed before or after AKI. Patients with sepsis pre-AKI were similar to patients with sepsis post-AKI in terms of dialysis requirements and length of stay. However, dialysis treatments were initiated earlier after AKI diagnosis in patients with sepsis pre-AKI than among patients who developed sepsis post-AKI $(4.1 \pm 5.6$ vs. $6.0 \pm 6.7$ days after AKI diagnosis; $p<0.008$ ).

\section{Discussion}

Acute kidney injury (AKI) is common among critically ill patients, and is associated with high mortality rates $(>50 \%)$ and substantial and wide-ranging morbidity $[2,19,20]$. Few patients with established AKI expire because of complications that are directly remediable with medications or dialysis, such as hyperkalemia or

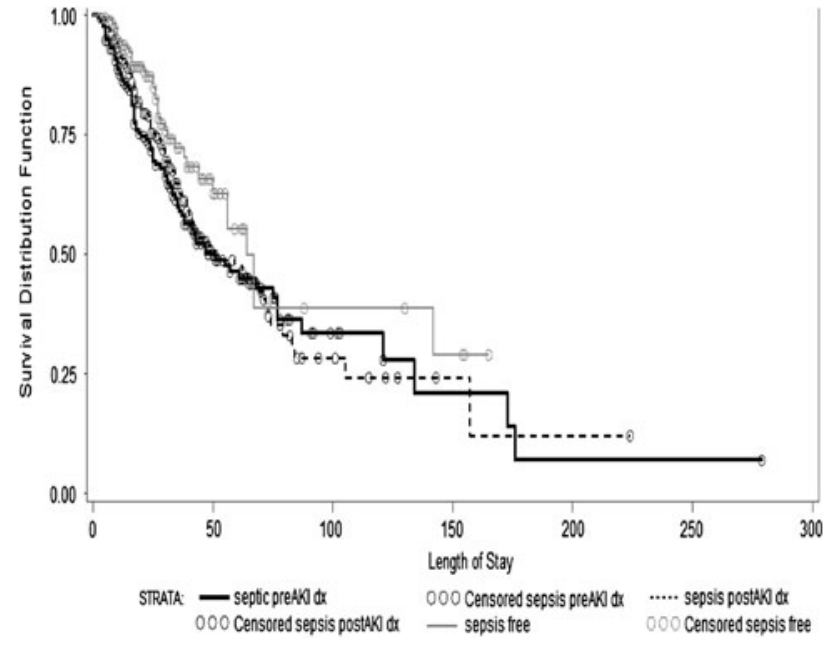

Fig. 2 Kaplan-Meier mortality estimates, by sepsis status over hospitalization ( $p=0.005$ between all groups)

pericarditis, and the mechanism(s) responsible for mortality and morbidity associated with AKI remain elusive. Many investigators have attempted to identify clinical factors that can serve as mortality predictors to aid in prognostic stratification after AKI, especially when the disease process is severe enough to require dialysis [21]. Previous studies have reported that sepsis causes or contributes to AKI in $32-48 \%$ of patients $[6,8,10]$. Whereas several studies have focused on sepsis-induced AKI, there are sparse data on the incidence, time course, risk factors, and prognosis of sepsis developing after AKI [13].

In the present study, $28 \%$ of patients had sepsis before AKI. Interestingly, $56 \%$ of patients who were not septic at the time of AKI diagnosis subsequently developed sepsis later in the hospital course. This percentage is similar to that previously reported in a smaller, single-center study of contrast-induced AKI (45\%; 21/47 patients) [13]. In our study, patients with sepsis had an absolute mortality rate $20 \%$ higher than patients who remained sepsis-free, regardless of when sepsis developed. It is noteworthy that 
Fig. 3 Outcomes according to sepsis status

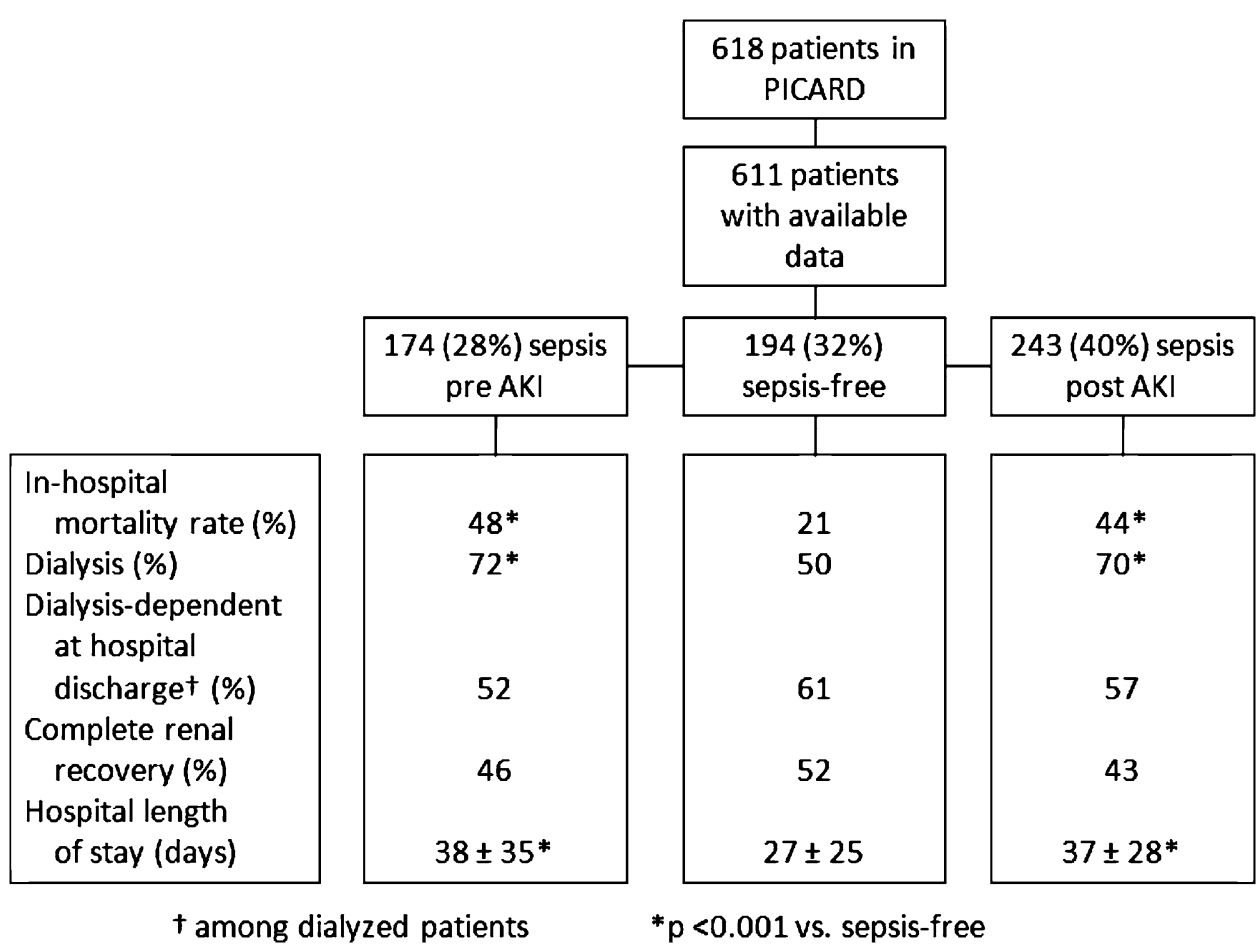

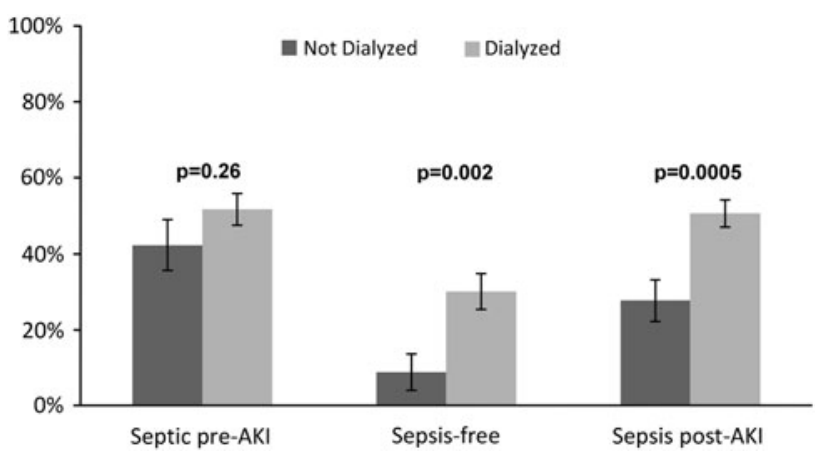

Fig. 4 In-hospital mortality rate stratified for sepsis and dialysis status

patients with AKI who remained sepsis-free had in-hospital mortality of "only" $21 \%$. This finding hints that studies focusing on surveillance for, and prevention of, infection may have the potential to relieve a fraction of the immense burden of mortality and morbidity currently experienced by critically ill patients with AKI.

Several factors have emerged as predictors of sepsis developing after AKI diagnosis. Previous studies have found that patients with sepsis-induced AKI were more likely to be oliguric than patients with AKI due to other causes [6]. Our study expands these results and showed that oliguria $\geq 3$ days was also associated with sepsis after AKI. Several previous studies have examined the association of fluid accumulation with sepsis [22, 23]. We recently reported that the amount and duration of fluid overload was strongly associated with mortality in this cohort [17]. When contemplating potential mechanisms explaining these associations, we note that it has been increasingly recognized that fluid accumulation leads to soft tissue and gut edema, which can impair barriers to infection; in particular, bowel edema may facilitate translocation of gut flora, potentially contributing to the development of sepsis and multiorgan failure [24-26].

Acute kidney injury has also been recognized as an immunocompromised state, associated with impaired monocyte cytokine production and elevated plasma cytokine levels [27]. Previous studies showed that patients with sepsis-induced AKI had higher severity of illness scores compared with patients with other causes of AKI [6]. Prior use of steroids and a higher severity of illness score emerged as predictors of sepsis in our study, possibly representing additional effects on the immune response. Interestingly, invasive non-surgical procedures performed after the diagnosis of AKI was established were associated with the development of sepsis, independent of the provision of dialysis. Although dialysis was an important predictor of sepsis after AKI diagnosis, the time to develop sepsis was similar in patients who did and did not require dialysis and in whom a dialysis catheter was or was not installed, suggesting that dialysis catheter is not the only, or necessarily the most important, source of sepsis post-AKI. Dialysis modality (continuous vs. intermittent) was unrelated to the incidence or time to develop sepsis. Contamination of replacement fluids may rarely occur during CRRT [28], and in IHD, backfiltration of non-sterile dialysate (particularly when dialysis is performed without concomitant ultrafiltration) may result 
in exposure to lipopolysaccharide and/or other contaminants that could contribute to sepsis or SIRS. Other as yet undetermined factors associated with dialysis might explain the association of dialysis and sepsis after AKI.

Our study has several strengths. We included patients from five tertiary care academic medical centers across the USA with different demographics and clinical conditions, increasing the generalizability of our results. Patients had detailed data on their sepsis status serially during hospitalization. There are also important limitations. First, only patients with a nephrology consultation were included. Patients, or their proxies, were required to sign informed consent [29]. Thus, patients included in PICARD may be slightly healthier than "all comers" with AKI in intensive care units. Second, since sepsis is a clinical diagnosis, its diagnosis could have been delayed in some patients. It is also possible that patients with "smoldering" infection prior to diagnosis of AKI could have been misclassified as having sepsis post-AKI. Third, we did not have data on the exact etiology of sepsis with ICD-9 codes and positive blood culture results for all patients, although in practice, approximately $50 \%$ of patients with severe sepsis demonstrate bacteremia at the time of diagnosis [30]. As mentioned, although we found a high incidence of sepsis post-AKI, we have not assessed the underlying mechanisms leading to sepsis in these patients. Previous data from PICARD showed abnormalities in several pathways, including cytokines, insulin resistance, and oxidative stress [27, 31, 32]. Additionally, we have identified key factors with biological plausibility in imparting additional risk (e.g., fluid accumulation, invasive procedures, and the provision of dialysis). A better knowledge of the focus of infections and specific preventive measures against nosocomial infections could have helped to better understand the pathophysiology of sepsis post-AKI. We did not have data on specific prophylactic measures applied in all or any of the hospitals participating in PICARD. However, standard prophylactic measures for infection control were followed in all the centers.

\section{Conclusions}

In this study, more than half of patients with AKI free of sepsis at the time of AKI diagnosis developed sepsis during hospitalization, and half of them within 5 days after AKI diagnosis. The development of sepsis following AKI has a similar prognosis as sepsis occurring before AKI diagnosis and can contribute to the overall poor prognosis in this patient population. Prospective studies are required to assess the derangements in host response that occur following AKI. Once the mechanisms underlying sepsis pre- and post-AKI are better understood, a well-informed clinical trial could be designed in an effort to reduce the frequency of, and adverse consequences caused by, sepsis following AKI. New strategies might help to reduce the exceptionally high rate of mortality and morbidity associated with AKI in the critically ill.

Acknowledgments The study was supported by the following research grants: National Institutes of Health: NIH-NIDDK RO1DK53412, RO1-DK53411, and RO1-DK53413. Josée Bouchard is a recipient of a research fellowship from the Kidney Foundation of Canada.

Open Access This article is distributed under the terms of the Creative Commons Attribution Noncommercial License which permits any noncommercial use, distribution, and reproduction in any medium, provided the original author(s) and source are credited.

\section{References}

1. Uchino S, Kellum JA, Bellomo R, Doig GS, Morimatsu H, Morgera S, Schetz M, Tan I, Bouman C, Macedo E, Gibney N, Tolwani A, Ronco C (2005) Acute renal failure in critically ill patients: a multinational, multicenter study. JAMA 294:813-818

2. Chertow GM, Burdick E, Honour M, Bonventre JV, Bates DW (2005) Acute kidney injury, mortality, length of stay, and costs in hospitalized patients. J Am Soc Nephrol 16:3365-3370

3. Waikar SS, Curhan GC, Wald R, McCarthy EP, Chertow GM (2006) Declining mortality in patients with acute renal failure, 1988 to 2002 . J Am Soc Nephrol 17:1143-1150
4. Joannidis M, Metnitz B, Bauer P, Schusterschitz N, Moreno R, Druml W, Metnitz PG (2009) Acute kidney injury in critically ill patients classified by AKIN versus RIFLE using the SAPS 3 database. Intensive Care Med 35:1692-1702

5. Joannidis M, Metnitz PG (2005) Epidemiology and natural history of acute renal failure in the ICU. Crit Care Clin 21:239-249

6. Bagshaw SM, Uchino S, Bellomo R, Morimatsu H, Morgera S, Schetz M, Tan I, Bouman C, Macedo E, Gibney N, Tolwani A, van Oudemans-Straaten HM, Ronco C, Kellum JA (2007) Septic acute kidney injury in critically ill patients: clinical characteristics and outcomes. Clin J Am Soc Nephrol 2:431-439
7. Bagshaw SM, Lapinsky S, Dial S, Arabi Y, Dodek P, Wood G, Ellis P, Guzman J, Marshall J, Parrillo JE, Skrobik Y, Kumar A (2009) Acute kidney injury in septic shock: clinical outcomes and impact of duration of hypotension prior to initiation of antimicrobial therapy. Intensive Care Med 35:871-881

8. Bagshaw SM, George C, Bellomo R (2008) Early acute kidney injury and sepsis: a multicentre evaluation. Crit Care 12:R47

9. Oppert M, Engel C, Brunkhorst FM, Bogatsch H, Reinhart K, Frei U, Eckardt KU, Loeffler M, John S (2008) Acute renal failure in patients with severe sepsis and septic shock - a significant independent risk factor for mortality: results from the German Prevalence Study. Nephrol Dial Transpl 23:904-909 
10. Neveu H, Kleinknecht D, Brivet F, Loirat P, Landais P (1996) Prognostic factors in acute renal failure due to sepsis. Results of a prospective multicentre study. The French Study Group on Acute Renal Failure. Nephrol Dial Transpl 11:293-299

11. Yegenaga I, Hoste E, Van Biesen W, Vanholder R, Benoit D, Kantarci G, Dhondt A, Colardyn F, Lameire N (2004) Clinical characteristics of patients developing ARF due to sepsis/ systemic inflammatory response syndrome: results of a prospective study. Am J Kidney Dis 43:817-824

12. Hoste EA, Lameire NH, Vanholder RC, Benoit DD, Decruyenaere JM, Colardyn FA (2003) Acute renal failure in patients with sepsis in a surgical ICU: predictive factors, incidence, comorbidity, and outcome. J Am Soc Nephrol 14:1022-1030

13. Levy EM, Viscoli CM, Horwitz RI (1996) The effect of acute renal failure on mortality. A cohort analysis. JAMA 275:1489-1494

14. Mehta RL, Pascual MT, Soroko S, Savage BR, Himmelfarb J, Ikizler TA, Paganini EP, Chertow GM (2004) Spectrum of acute renal failure in the intensive care unit: the PICARD experience. Kidney Int 66:1613-1621

15. (1992) American College of Chest Physicians/Society of Critical Care Medicine Consensus Conference: definitions for sepsis and organ failure and guidelines for the use of innovative therapies in sepsis. Crit Care Med 20:864-874

16. Goldstein SL, Somers MJ, Baum MA, Symons JM, Brophy PD, Blowey D, Bunchman TE, Baker C, Mottes T, McAfee N, Barnett J, Morrison G, Rogers K, Fortenberry JD (2005) Pediatric patients with multi-organ dysfunction syndrome receiving continuous renal replacement therapy. Kidney Int 67:653-658

17. Bouchard J, Soroko SB, Chertow GM, Himmelfarb J, Ikizler TA, Paganini EP, Mehta RL (2009) Fluid accumulation, survival and recovery of kidney function in critically ill patients with acute kidney injury. Kidney Int $76: 422-427$
18. Vincent JL, Moreno R, Takala J, Willatts S, De Mendonca A, Bruining H, Reinhart CK, Suter PM, Thijs LG (1996) The SOFA (Sepsis-related Organ Failure Assessment) score to describe organ dysfunction/failure. On behalf of the Working Group on SepsisRelated Problems of the European Society of Intensive Care Medicine. Intensive Care Med 22:707-710

19. Lassnigg A, Schmid ER, Hiesmayr M, Falk C, Druml W, Bauer P, Schmidlin D (2008) Impact of minimal increases in serum creatinine on outcome in patients after cardiothoracic surgery: do we have to revise current definitions of acute renal failure? Crit Care Med 36:1129-1137

20. Lassnigg A, Schmidlin D, Mouhieddine M, Bachmann LM, Druml W, Bauer P, Hiesmayr M (2004) Minimal changes of serum creatinine predict prognosis in patients after cardiothoracic surgery: a prospective cohort study. J Am Soc Nephrol 15:1597-1605

21. Chertow GM, Soroko SH, Paganini EP, Cho KC, Himmelfarb J, Ikizler TA, Mehta RL (2006) Mortality after acute renal failure: models for prognostic stratification and risk adjustment. Kidney Int 70:1120-1126

22. Payen D, de Pont AC, Sakr Y, Spies C, Reinhart K, Vincent JL (2008) A positive fluid balance is associated with a worse outcome in patients with acute renal failure. Crit Care 12:R74

23. Vincent JL, Sakr Y, Sprung CL, Ranieri VM, Reinhart K, Gerlach H, Moreno R, Carlet J, Le Gall JR, Payen D (2006) Sepsis in European intensive care units: results of the SOAP study. Crit Care Med 34:344-353

24. MacFie J, O'Boyle C, Mitchell CJ, Buckley PM, Johnstone D, Sudworth P (1999) Gut origin of sepsis: a prospective study investigating associations between bacterial translocation, gastric microflora, and septic morbidity. Gut 45:223-228

25. Gatt M, Reddy BS, MacFie J (2007) Review article: bacterial translocation in the critically ill-evidence and methods of prevention. Aliment Pharmacol Ther 25:741-757
26. Brusselaers N, Monstrey S, Colpaert K, Decruyenaere J, Blot SI, Hoste EA (2010) Outcome of acute kidney injury in severe burns: a systematic review and meta-analysis. Intensive Care Med 36:915-925

27. Himmelfarb J, Le P, Klenzak J, Freedman S, McMenamin ME, Ikizler TA (2004) Impaired monocyte cytokine production in critically ill patients with acute renal failure. Kidney Int 66:2354-2360

28. Moore I, Bhat R, Hoenich NA, Kilner AJ, Prabhu M, Orr KE,

Kanagasundaram NS (2009) A microbiological survey of bicarbonatebased replacement circuits in continuous veno-venous hemofiltration. Crit Care Med 37:496-500

29. Chertow GM, Pascual MT, Soroko S, Savage BR, Himmelfarb J, Ikizler TA, Paganini EP, Mehta RL (2003) Reasons for non-enrollment in a cohort study of ARF: the Program to Improve Care in Acute Renal Disease (PICARD) experience and implications for a clinical trials network. Am J Kidney Dis 42:507-512

30. Bone RC, Fisher CJ Jr, Clemmer TP, Slotman GJ, Metz CA, Balk RA (1989) Sepsis syndrome: a valid clinical entity. Methylprednisolone Severe Sepsis Study Group. Crit Care Med 17:389-393

31. Himmelfarb J, McMonagle E, Freedman S, Klenzak J, McMenamin E, Le P, Pupim LB, Ikizler TA, The PG (2004) Oxidative stress is increased in critically ill patients with acute renal failure. J Am Soc Nephrol 15:2449-2456

32. Basi S, Pupim LB, Simmons EM, Sezer MT, Shyr Y, Freedman S, Chertow GM, Mehta RL, Paganini E, Himmelfarb J, Ikizler TA (2005) Insulin resistance in critically ill patients with acute renal failure. Am J Physiol Renal Physiol 289:F259-F264 